of the importance to take into account the specificities of older people during the application of emergency measures and the recovery period of a community.

Prehosp Disaster Med 2011;26(Suppl. 1):s37-s38

doi:10.1017/S1049023X11001348

(A134) Special Needs of the Elderly During Disasters Suggested Strategies and Lessons Learned from the 2007 Tulsa, Oklahoma Ice Storm

J. Gulden, ${ }^{1}$ M.K. Stewart, ${ }^{2}$ C.E. Stewart ${ }^{2}$

1. Emergency Management Support, M5G2V1, Canada

2. Department of Emergency Medicine, 74137, United States of America

Special Needs of the Elderly During Disasters Suggested Strategies and Lessons Learned from the 2007 Tulsa, Oklahoma Ice Storm. On the evening of December 7, 2007 an ice storm occurred in the south central United States causing severe power outages in Tulsa, Oklahoma. In Oklahoma alone, 900,000 people were without power for periods of up to 3 weeks. Approximately $13.2 \%$ of the population in Oklahoma aged 65 + live in institutional care (2000 US Census Report). There are 498 nursing home facilities in Oklahoma serving this majority of this population (a small percentage live in other types of care facilities). Of these facilities 143 lost electrical power for up to six days, 88 lost power but had generators available within 24 hours or less, and 55 had no alternative source of power. Of the 55 without power, 42 relocated residents. Critical infrastructure failures during natural disasters can create a cascade of direct and indirect losses due to a number of physical, social and economic interdependencies that exist (Rinaldi, Peerenboom \& Kelly 2001). The elderly present some unique characteristics that make them more vulnerable during natural disasters. Chronic health problems, physical mobility and cognitive limitations make them unable to adequately prepare for disasters (Aldrich \& Benson 2008) making them entirely dependent on the facilities. In the three years since the storm the Oklahoma Disaster Institute has focused its efforts on developing and implementing mitigation strategies to address power loss in nursing homes. These strategies included discussions with the Department of Health, Emergency Medical Services Authority and local hospital officials. As a result of these discussions, table-top exercises were conducted in multiple venues, and speakers from the Department of Health, EMSA, and emergency management were arranged in an Extended Care Facility Workshop. This paper will look at lessons learned, mitigation strategies and successes in protecting the elderly in nursing homes during natural disasters.

Prehosp Disaster Med 2011;26(Suppl. 1):s38

doi:10.1017/S1049023X1100135X

(A135) Preliminary Results of Post-Flooding Impacts on Rural Elderly in Hainan Province, China

E.Y.Y. Chan, ${ }^{1}$ C.L.Y. Lin ${ }^{1}$ P.P.Y. Lee, ${ }^{1}$ I. Zheng, ${ }^{2}$

E.Y.L. Cheung, ${ }^{1}$ S.C. Lam ${ }^{2}$

1. CCOC, School of Public Health and Primary Care, NT, Hong Kong

2. Department of Ophthalmology and Visual Science, Hong Kong, Hong Kong

Background: Limited information is available on the health outcomes of the rural older population in developing countries is affected by disasters. In October 2010, Hainan Province experienced severe flooding following heavy rains. Nearly four million people were affected and many had undergone resettlement. This study investigated the impacts of the flooding on people living in the disaster-affected rural communities. The findings were compared with baseline information collected in 2010 about health issues in rural villages in Hainan. Health outcome comparisons also were made between ethnic groups (Han versus $\mathrm{Li}$ ).

Methods: A two-stage cluster-sampling, cross-sectional postdisaster study was conducted. The entire Hainan Island was categorized into ranks of different severity in rainfall amount and associated damage in October (most severe, intermediate, least severe). The county with the most rainfall and the most severe ranking and the one with least rainfall and the least severe ranking were identified. In each county, one Han and one Li village were chosen by using a computer-generated random number, so four villages were sampled in total. More than 100 individuals $\geq 50$ years of age were interviewed by face-to-face survey. Data on disaster-related injuries, socio-demographic information, non-communicable disease, lifestyle, and mental health were collected.

Results: Findings indicated the severity of impact was associated with self-reported health outcomes of older population. Gender and ethnic differences were found in reported health outcomes. Predictors of adverse post-disaster health outcomes in older populations in rural communities were identified.

Conclusions: The results demonstrated significant differences in the impacts of flooding in rural populations. Targeted services and interventions should be planned to address the disparity and meet the physical and mental health needs post-disaster.

Prehosp Disaster Med 2011;26(Suppl. 1):s38

doi:10.1017/S1049023X11001361

\section{(A136) Eldery in Emergency}

M.C. Saenz

Pshycological Support, Lomas de Zamora, Argentina

Elderly in emergency - Presentation: Psychosocial support is essential to prevent mental health disorders in the elders subjected to trauma in emergencies that induces to isolation as well as risks or vulnerability for them and their environment. Financial crisis, natural disasters, attacks, poverty, violence and loneliness in the social environment turn threatening for them. Reality becomes hard and produces disorganization in mental health.

Objectives: Elder people who have gone through one or more of the following situations are the ones who are prone to develop intense or immediate character disorder. With strategies that increase the existing psychosocial protection factors stress at different intervention levels is lowered. Those who have gone through one or more violent experiences are the ones who are prone to develop intense or immediate character disorder. Cultural transferring (between adults and between adults and children) and mutual help between adults and children is held. Methodology: Cognitive processing factors associated to each individual's anxiety: stress, depression, loneliness, panic attacks etc. Some techniques have been developed to understand emotions and learn how to manage them: songs, classic tales, puppets, advertisements and anagrams, Kessen cards, etc. All the material and the results were evaluated with clinic tests and professional help. 